Gazi University
Journal of Science
http://dergipark.gov.tr/gujs

\title{
A Case Study on Reducing Setup Time Using SMED on a Turning Line
}

\author{
Ramazan SAHIN ${ }^{*}$ (i) , Aycan KOLOGLU² ${ }^{(0)}$ \\ ${ }^{I}$ Gazi University, Department of Industrial Engineering, 06570, Ankara, Turkey \\ ${ }^{2}$ ORS Bearings Inc., 06800, Ankara, Turkey
}

\section{Highlights}

- This article focuses on the application of the SMED on a turning line.

- SMED, is one of the lean manufacturing techniques, used in reducing machine setup times.

- The productivity of the production line worked on has been increased.

\section{Article Info}

Received: 12 May 2020

Accepted: 13 Apr 2021

\section{Keywords}

Lean manufacturing Quick changeover Setup time reduction SME

\begin{abstract}
Today, manufacturers must meet customer demands in a shorter time with the best quality and lowest cost to survive in competitive environment. One way to achieve this is to reduce production costs by eliminating waste activities in a production system. Machine adjustment processes are the activities that do not create value, and Single Minute Exchange of Dies (SMED), lean manufacturing tool, has been developed to reduce these activities. In this paper we have performed a case study in a bearing manufacturing company to reduce the machine setup time on turning line using the SMED. The emphasis is given to both transferring internal activities into external ones as many as possible and minimizing the internal ones. The main results attained from the study indicate that the machine setup times were reduced more than $45 \%$ for the turning line. Consequently, machine capacities can be significantly increased by the application of SMED method.
\end{abstract}

\section{INTRODUCTION}

Increasing globalization has been pulling companies to more severe competition in which they are obliged to meet customers' demands on time with high quality and low cost. In addition, delivery operations need to be performed on a quick basis to survive and increase market share. As a consequence of the competition, customers not only determine the price of a product but they also request permanent discount on the price. Cost reduction, therefore, emerges as a convenient strategy to maintain profitability in the long term. When the cost reduction is of concern, lean manufacturing based strategies can be effectively applied.

Lean manufacturing is a well-known production philosophy that eliminates waste and non-value added factors as well as the costs of these activities in production of goods and services. Non value-added activities are defined as the time spent on activities that add costs but no value to an item from the customer's perspective. Customers admit paying for value added activity (i.e. raw material or production time) on the other hand they are generally not willing to pay for non-value added activities [1]. Lean manufacturing or lean philosophy pursues the way of creating more value by total elimination of waste, so it focuses on ensuring customer satisfaction from a more effective perspective. Lean philosophy strives to achieve a continuous value flow from supplier to the customer. It includes a set of tools for the identification and elimination of waste. These tools focus on certain aspects and areas of the manufacturing processes in order to eliminate waste and to improve quality. As stated by Chong et al. [2], some of the tools of lean philosophy include just-in-time, single-minute exchange of die (SMED), kanban system, Six Sigma quality control, Total Productive Maintenance, Poka-Yoke, Jidoka, and 5S. 
Most of the machines and machine lines in manufacturing plants are "shared resources". Hence, the same machines are used to produce different product types or different product variants within a given product family with a set-up involved when production is switched from one product type to another [3]. When losses in a company are taken into consideration, changeover time of dies can be regarded as one of the most important non-value added activity. So, the less the changeover time is, the more the cost reduction is. As shown in Figure 1 the changeover starts with the end of current production and continues to the first good part of the next production [4].

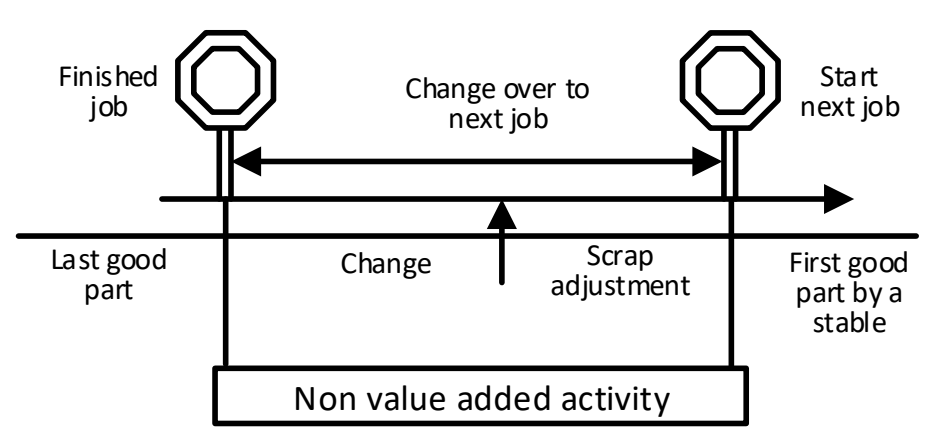

Figure 1. Representation of Changeover Time

The basic idea of SMED was found while changing dies of three large body-molding presses in Mazda Hiroshima plant in 1950 by Shigeo Shingo, who was the management consultant at the Japan Management Association. 19 years later, in 1969, with his studies at Toyota Motor Company, he reduced four hours of change over time to three minutes. During that study, Shingo had the first of a series of breakthroughs that would later become famous under the name of SMED [5].

In mass production systems, the most important reason of working with inventory is long set up time which lasts minutes or even hours. For higher productivity of machines or machine lines and lower employment costs, machine running time must be used 10 times longer than setup time. Only in this case will the machine be able to produce the same product for large batches. Otherwise, even if all other parameters are correctly made, implementation of lean production becomes impossible.

Shigeo Shingo, who consulted with Toyota and many other companies, realized as early as 1950 that reduction in set-up time is an obligation and that fact inspired hundreds of companies to apply these reduction techniques very quickly. Therefore, switching from one product to another took only a couple of minutes or less than one minute following the breakthroughs suggested by Shingo.

In the SMED philosophy, the machines do not produce products for stock, and they turn into incredibly flexible machines. Thus, by applying the method proposed by Shingo, the setup times are reduced [6]. Van Goubergen and Van Landeghem [7] presented three principal reasons why setup time reduction activities can be crucial to any manufacturer. These are: (1) to increase flexibility by conducting more changeovers and reducing lot size, (2) to increase bottleneck capacities in order to maximize the line availability for production, (3) to minimize the cost since production costs are related to equipment effectiveness.

Many companies have so far implemented SMED methodology for their production systems and obtained successful results. Reduction in setup time enables companies to become more flexible. Smaller batch sizes and higher product variations provide companies with the ability to quickly response to the customers' needs. Also SMED eliminate the bottleneck problem by reducing the setup time in bottleneck workstation. In this study, using SMED, one of the traditional lean manufacturing techniques, it is focused on the efficiency and cost reduction process that an enterprise needs in a competitive environment. It is aimed to increase effectiveness and efficiency by using real data within the scope of university-industry cooperation. 
The remainder of the paper is organized as follows. Related literature is given in the next section. Section 3 describes the main features of the SMED technique. Section 4 presents a real life SMED application for a turning machine of a supplier working in automotive industry.

\section{LITERATURE REVIEW}

SMED, is one of the lean manufacturing techniques used in reducing machine setup times. The purpose of SMED is to realize the setup times in less than ten minutes. The SMED literature provides us with large number of applications in various fields. Here, only some of these studies will be discussed.

Trovinger and Bohn [8] implemented SMED in the setup of high speed circuit board assembly. Consequently, they gained $\$ 1.5$ million annual profit and managed reduction of setup time at the rate of $80 \%$. McIntosh et al. [9] are used two basic mechanisms to evaluate which one of the two proposed methods is better. First method is done by altering the sequence of conducting tasks without any variation in the way of performing tasks and secondly by altering the existing tasks so that they can be completed more quickly. To point out the relation between SMED and equipment design, Cakmakci [10] implemented process capability analysis technique by using MATLAB. Cpk (process capability index) index is used to obtain a quantitative measurement by applying SMED methodology in designing equipment in automobile production. The results of that research showed that SMED is still a convenient method not only for manufacturing improvement but also for equipment/die design development. According to the top management decision Kusar et al. [11] implemented SMED on a CNC injection machine in 2010 and targeted 50\% reduction in setup time was achieved. Ulutas [4] conducted a SMED study on a press machine 5 meters in height and used for the production of refrigerator packaging sytrofoam. She proposed that the safety of workers can be enhanced by applying SMED and stressed that it can be done together on some tasks simultaneously and alone. Deros et al. [12] focused on reduction of both production costs and setup time by SMED study on battery assembly line. Abraham et al. [13] demonstrated that a great setup time reduction in the bottleneck BMS machine can be achieved by applying conventional SMED to the stamping production line. The setup time of the bottleneck machine was decreased by $75 \%$, leading to a significant improvement in the productivity of the production line. Van Goubergen and Van Landeghem [14] proposed an iterative approach for set-up reduction of such multi-stage manufacturing lines. In this situation set-up activities need to be performed on different machines or workstations of the line by different persons. Bevilacqua et al [15] have done a study to reveal the importance of quick changeovers in the packaging line of a pharmaceutical company. They used an integrated setup reduction approach consisting of lean manufacturing techniques such as SMED, Kanban, 5S and Total Productive Maintenance. Filla [16] has applied SMED to High Mixing operations in a flat glass processing company that produces hundreds of products. Soberi and Ahmad [17] proposed a new hybrid method that integrates the original SMED and Analytical Hierarchy Process. Karasu and Salum [18] proposed a fuzzy inference system application for parameter adjustments during changeovers on plastic injection molds. They integrated this system into SMED applications to reduce production lot size. Otur et al. [19] have made an SMED application in their articles to minimize total time of the color changeover process for plastic bottles production at one of the companies in the cosmetic sector. In this study, Monteiro et al. [20] firstly have had defined the basic processes and flow charts using value stream mapping method in order to increase productivity and eliminate waste in a metal processing company. After the implementation of SMED on vertical and horizontal milling machines, it has been observed that the implementation of SMED contributed to $40 \%$ and 57\% reduction in setup time, respectively. Vieira et al. [21] SMED applied its methodology to a group of cold profiling machines at a company in the metalworking industry in Portugal, consisting of five different profiling machines. The results of the SMED implementation showed an average improvement of $10.8 \%$ in Overall Equipment Effectiveness. Akyurt and Eren [22] applied the SMED methodology on the injection machines in the company that produces test and assembly parts for the automotive and electrical industries. They also conducted a 5S study prior to the SMED study. At the end of the study, they reported that the setup time reduced from 65.30 minutes to 23.62 minutes. Çelik [23] has made a study to develop a method that will contribute to the reduction of the intensity levels of the factors affecting the changeover time. He proposed Taguchi-based SMED methodology for this. In his study, he compared the Taguchibased SMED with the traditional SMED method. According to the obtained results, the Taguchi-based SMED method provided an additional 216 minutes' improvement in total setup time. Yalçın et al. [24] in 
their study, used the SMED method to improve the mold setup times in the press in a steel pipe company that produces pipe fittings in the heavy industry sector. In the study performed by Vieira et al. [25], the SMED methodology was applied to deep drawing machine in the automotive industry, reducing $38 \%$ of total machine setup time and increasing $7.7 \%$ of Overall Equipment Effectiveness.

For more detailed information on SMED, please refer to the recently published review articles [1, 26, 27].

\section{SMED}

The logic of Shingo's method [28] is a classification of all setup activities into internal and external ones. Internal setup activities can be performed only when the machine is shut down such as mounting or removing dies. On the other hand, external setup is group of setup activities while the equipment is still running (e.g., transporting dies to or from storage). These two kinds of activities are extremely important in the implementation of SMED. Improved methods are implemented in different and consecutive steps. SMED is mainly performed in four steps.

The preliminary step of SMED is the observation of the ongoing process. At this stage, the machine operator and / or the operator performing the mold change should be involved in the process monitoring. The duration of the activities carried out in this process are recorded with the help of a camera or by talking with the operator performing the activity. The accuracy of the data obtained at this stage is crucial to the success of SMED. Figure 2 depicts Shingo's [28] discussion and presentation of concepts, techniques and examples comprehensively as a hierarchical structure, where awareness at the three levels of the hierarchy may assist the changeover practitioner in different aspects. The other three stages proposed by [28] are described in Figure 2.

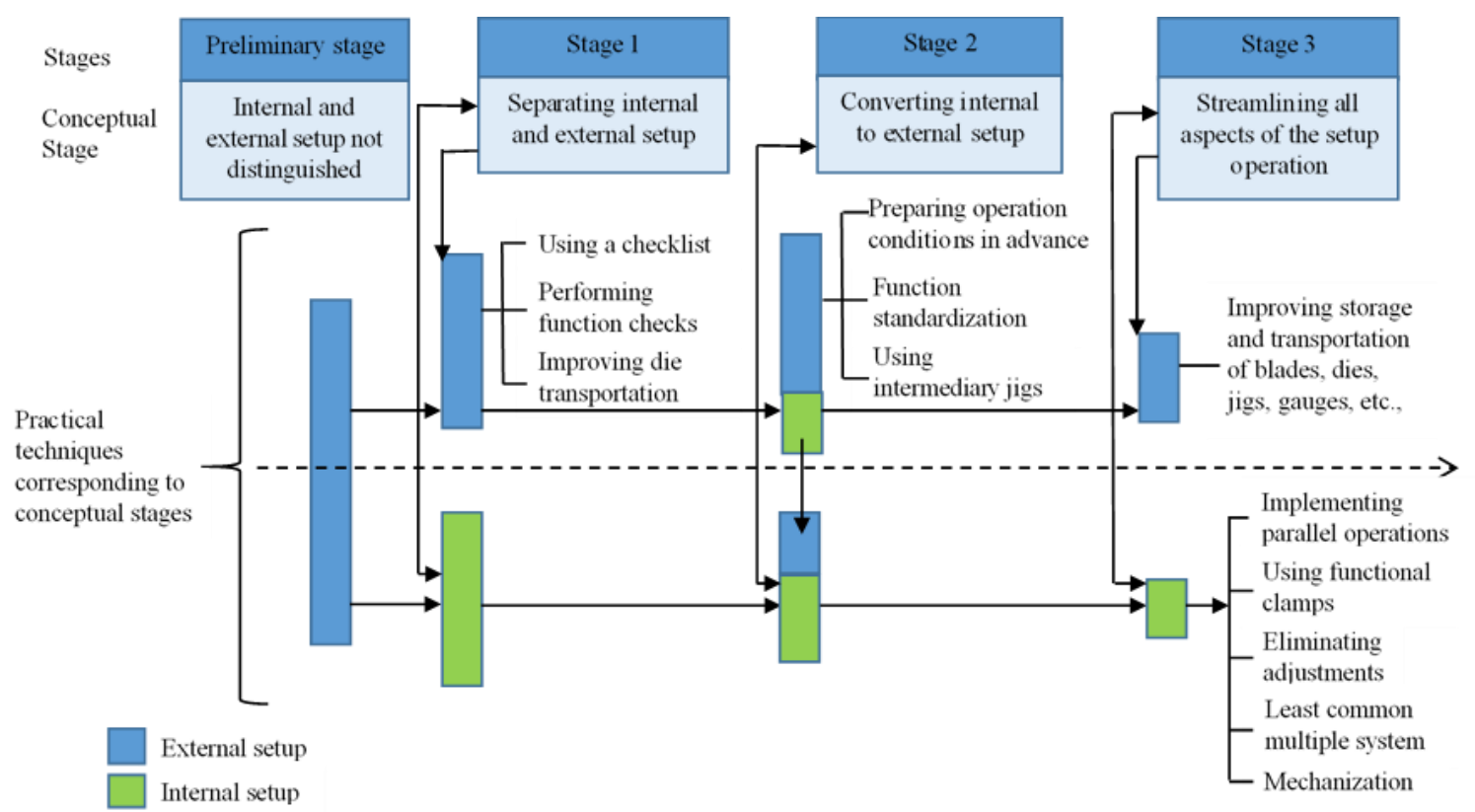

Figure 2. SMED; Conceptual Stages and Practical Techniques [28]

The first step is the separation of internal and external setup activities. At this stage the SMED focuses on separating and classifying external and internal setup activities. Figure 2 shows how setup time improvement techniques are applied step-by-step within the SMED methodology. As shown in Figure 2, at the beginning internal and external setup activities are not separated. These activities are performed randomly by the operator. Although internal setup tasks can easily be converted external setup tasks, operators prefer to do it internally. Converting internal setups to external one can lead to a reduction in setup time by as much as $30 \%$ to $50 \%$. SMED uses three methods in this step: checklists, function controls, and improved handling of dies and other parts. 
The second step of SMED is the conversion of internal setup operations into external setup operations in order to convert internal activities into external activities, setup must be examined as if it were the first time and checkup all activities and purpose of these activities. Advanced preparation of operating conditions and function standardization can be used to convert internal activities to external ones.

The third step of SMED is streamlining of all aspects of the setup operations. All setup operations including internal and external ones are finally improved. Re-inspection and re-designing tools, improvement on tool storage and transportation can enhance external setup activities. Tools conditions should be constantly checked to minimize disruption caused by repairs. On the other hand, internal setup reorganization can be managed by applying parallel operations or eliminating unnecessary adjustments.

\section{CASE STUDY: SMED IMPLEMENTATION IN A TURNING LINE}

In this paper, a SMED application in a bearing manufacturing plant was discussed. The company operates as a supplier of numerous industries including automotive and white appliances sectors. All processes for bearing production ranging from raw material to packaging for retailing take place in the factory. In the preliminary analyses of the manufacturing equipment, the setup losses in the machines were determined. This helped managerial board to see where the highest improvement opportunity was. As shown in Figure 3 , the highest setup loss was found in forging machines. However, losses in forging machines are within acceptable limits for this industry and there are few of these machines on the production line. The turning line consists of 17 machines and the losses in these machines can be reduced. The sum of the improvements made to each of the 17 machines was considered a major gain for the business. For these reasons, it was decided to implement the SMED application in the turning (trepanning) line. Throughout the rest of the study, SMED implementation on a turning line will be discussed.

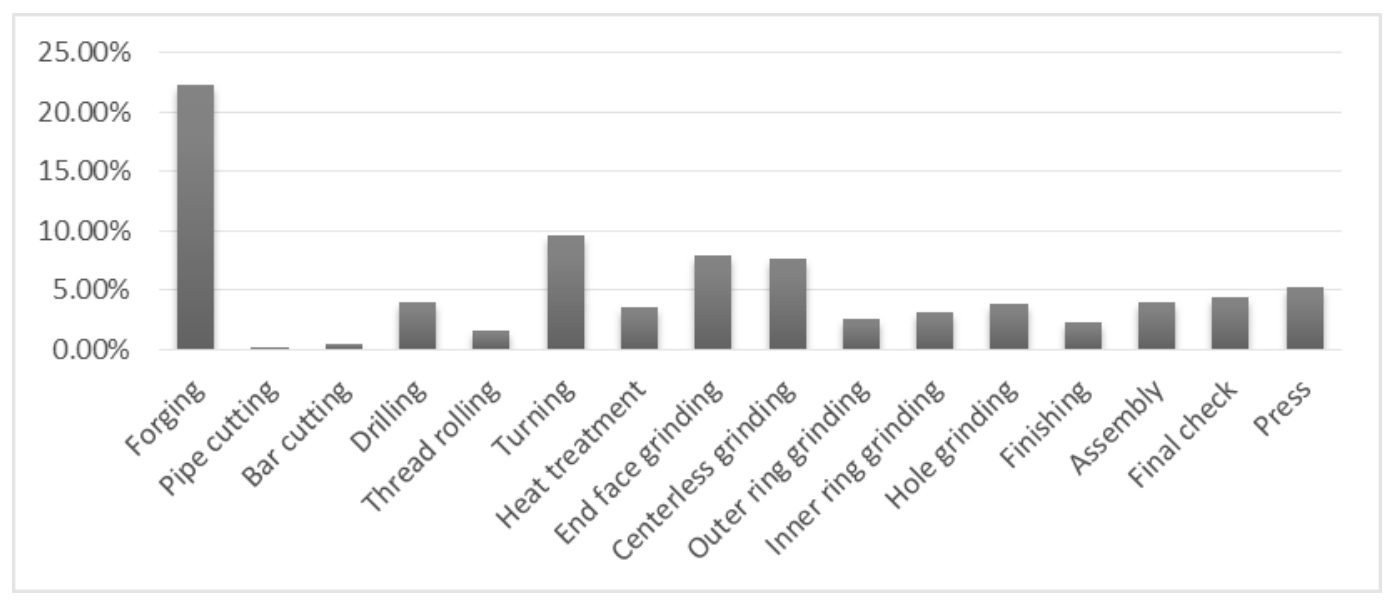

Figure 3. Setup Losses in Machines

Turning (trepanning) line A is made up of 17 machines. 16 of these machines are turning lathes. A press machine is also used in the line, in order to separate inner and outer rings from each other. For SMED implementation, the turning line A was selected because in there, most of the setup operations took place, and various types of parts are produced. The simplified layout of lathes and press machine of line A is given in Figure 4. Before the SMED application in turning line A, setup time took approximately 1.5-2 shifts. The turning line A could actually be considered as three sequentially ordered production lines. Six of the turning machines (1-6) at the beginning of the line have very similar processing capabilities. These can be started together but independently from the rest of the machines of the line A. When these machines are started, they start production of inputs of the next four machines (7-10). If the start is given for these six machines, they provide buffer stock for four of the turning lathes 7-10. In lathes 7-10, various turning processes are carried out. Then, there is a press machine to separate a donut ring into two parts as inner ring and outer ring. After this stage, 2 machines (12-13) are used for inner ring processes and 4 machines (1417) are used for outer ring processes. Processing of inner ring and outer ring can be started independently 
but if they are not produced concurrently, line cannot continue production. Setting up and starting of a line should be understood as the starting of the mass production in all of the lines.

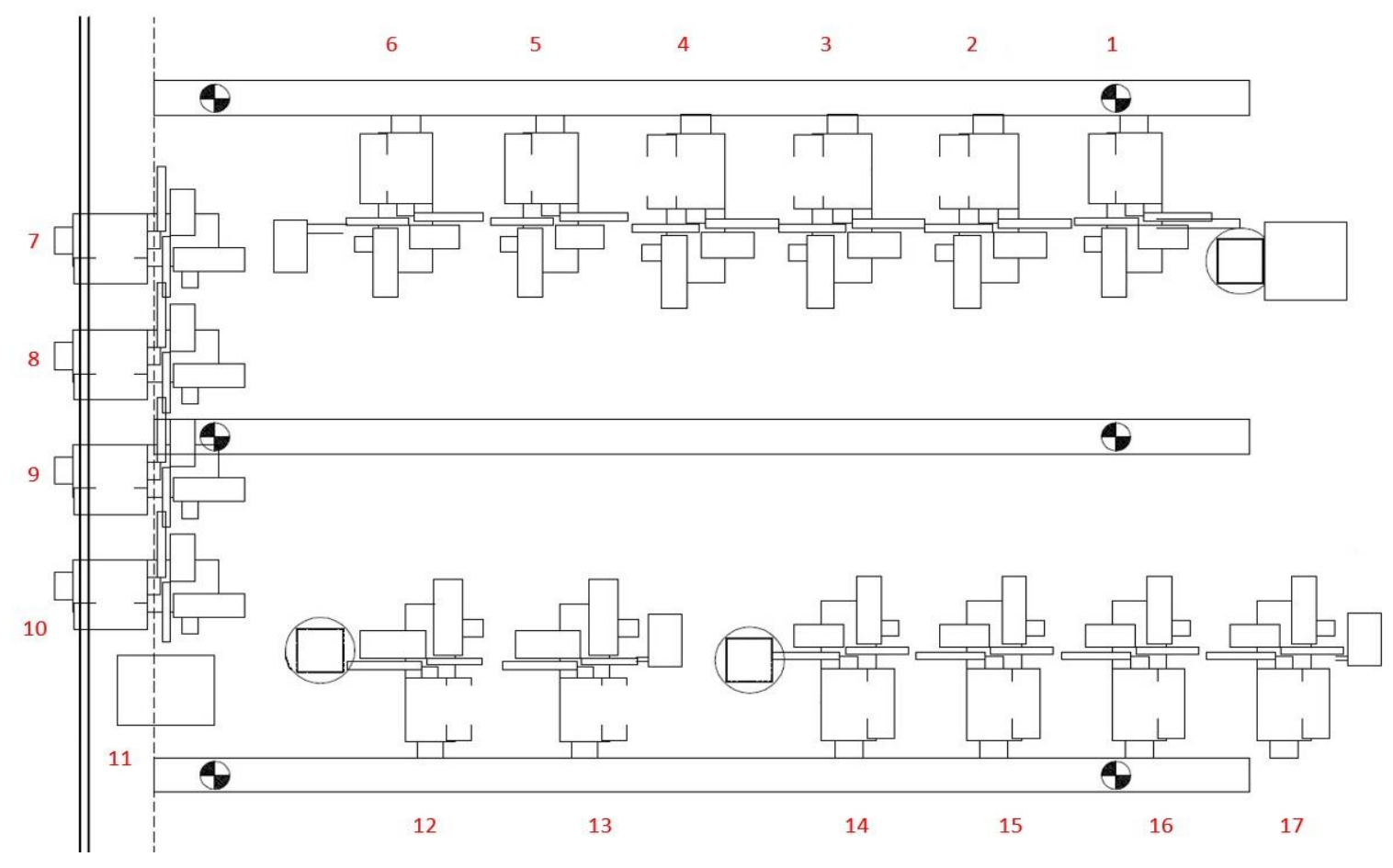

Figure 4. Machine layout of Line A

\subsection{Observing Setup Time}

The first stage of the SMED application is setup time analysis. If the analysis is not applicable, the results will be wrong and misleading. Therefore, this stage should be handled carefully.

At the stage of setup time analysis, a frequently performed setup operation was determined. After the preceding production, every activity was recorded until the start of succeeding production. Activities were determined based on the interviews with operators who took role during the setup. At the end of this analysis, the following questions were answered: (a) Which activities are carried out? (b) What is the sequence of the processes? (c) Who carries out the processes (quality, production, equipment)? After examination of the interviews with operators and the images captured by video recording, setup analysis study was accomplished. Thus, setup processes were classified. It was found out that the total setup time was 1418 minutes. Since two operators are responsible from the setup operations and considering the distribution of tasks among them, setup time of the line was taking 749 minutes. Namely, when two operators perform the setup operations, changeover time between two different types of products took 749 minutes. Grouping of the activities during setup analysis is shown in Figure 5. 


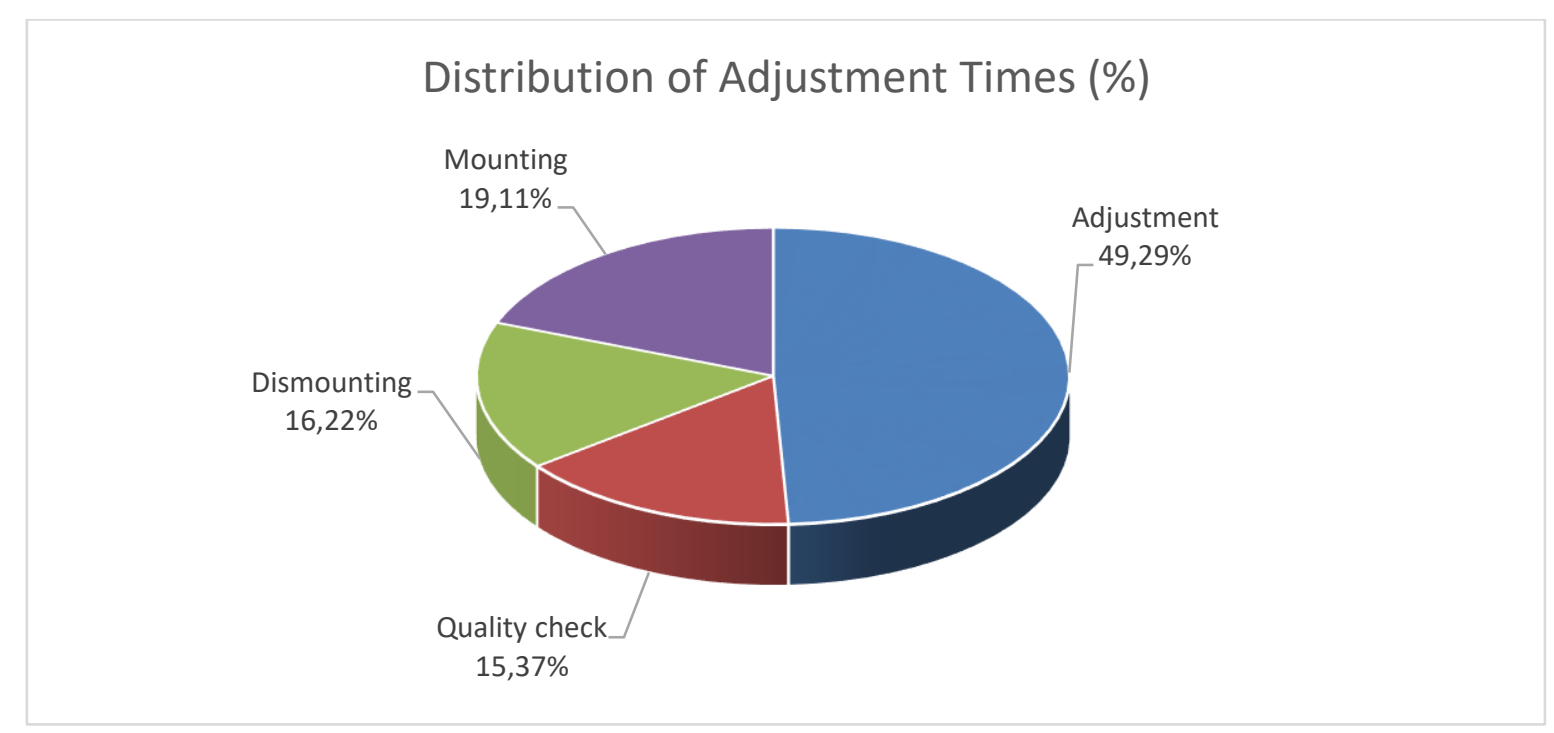

Figure 5. Time Loss Pie-Chart of Turning Line A

\subsection{Identifying Internal and External Setup}

At the present stage, the setup activities should be classified as internal and external setups. Setups are classified based on the status of the machine during the setup activities. If a setup activity can be accomplished without stopping machine, this is called an external setup. However, the setup activities, those can only be carried out while the machine is shut down, are called internal setups.

During the observation period, it was detected that the machines were stopped in all adjustment steps except for the changing of the chutes and gauge pieces. A chute is a type of small transportation rail, through which parts are transferred between machines. Results of the analyses revealed that $19 \%$ of the total setup time was occupied by external setup activities. The remaining $81 \%$ of the total setup time consisted of internal setup activities.

\subsection{Converting Internal Setup Activities to External Setup Activities}

After the exact classification of setup activities as internal and external setups, the work group developed ways to convert internal setups into external setup. Obviously, that helped to increase available time of machines.

Firstly, the issue of tool transfer from tool room to the trepanning line was handled. Previously, it was taking 10 minutes to carry and setup the tools. During this transfer time, the machine was kept turned off and no action was taken. In order to reduce time, both machine and setup operators were trained. According to the new plan, the setup operators will be informed by the machine operators in sufficient time before the setup process. Thus, it was ensured that the necessary tools needed on time are next to the machine. Thanks to these regulations, the time spent both for the transfer of tools and for internal setup has been eliminated. To process the next product, the machines had to be adjusted, the collet chucks had to be processed. This process is carried out on lathes, and the operators doing this had to be very careful Otherwise, it causes the parts to become slightly oval. SMED team observed that this could be converted into external setup activity by preparing tools in advance of the setup. A grinding process was introduced in order to eliminate factors that could cause parts to lose their design tolerances. Thus, reprocessing of tools were eliminated and 291 minutes of setup time was saved.

During the setup of trepanning machines 7-10, dimensions of their cutting tools were being sharpened. Processing of the cutting tools was taking approximately 19 minutes. Sharpening of cutting edges of tools requires attention of setup personnel. Otherwise, cutting tools are wasted. Previously, machines were stopped for this operation but SMED team concluded that it could be converted into an external setup. After 
consulting to the managerial board of the company, trepanning cutting tools were decided to be outsourced. Sharpened at the factory and purchased cutting tools are given in Figure 6. That led to total elimination of setup for the cutting tools of trepanning machines (7-10). This decision provided some additional benefits to the company such as reduction of costs of cutting tools by $32 \%$ and increasing their usable life by $300 \%$.

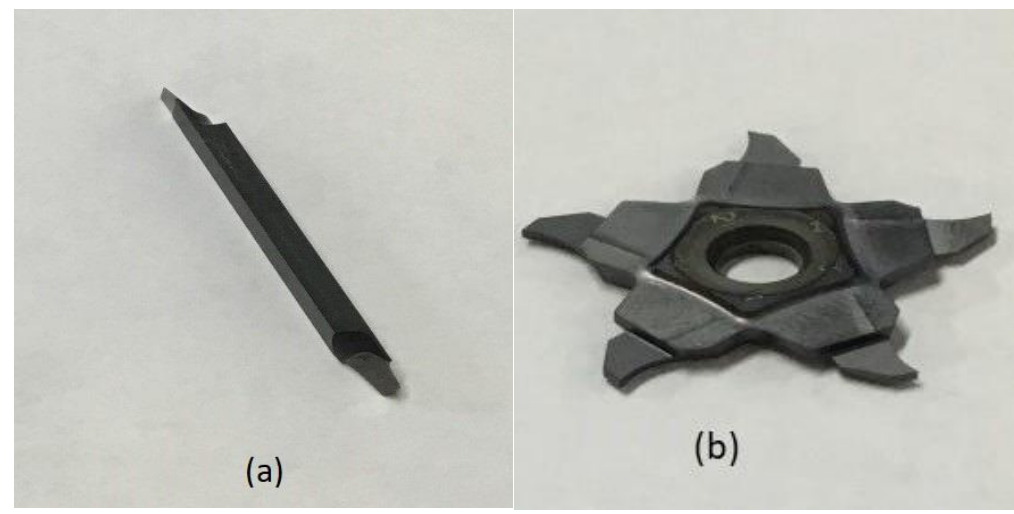

Figure 6. Cutting tools: (a) Made in the company (b) Outsourced

\subsection{Streamlining All Aspects of the Setup Operations}

At the last step of SMED, all the processes were investigated for further improvement opportunities. Firstly, bolts on the chucks were examined and 527 bolts were counted for the turning line (17 machines) in total. Namely, in each setup on a machine, 30 bolts on average were being screwed by using screwdriver or allen wrench (hex key). By adopting an operator's proposal, these bolts decided to be tightened by pneumatic impact wrenches. By using this equipment for mounting and dismounting of dies, setup time was reduced by 28 minutes. The developed equipment can be seen in Figure 7.

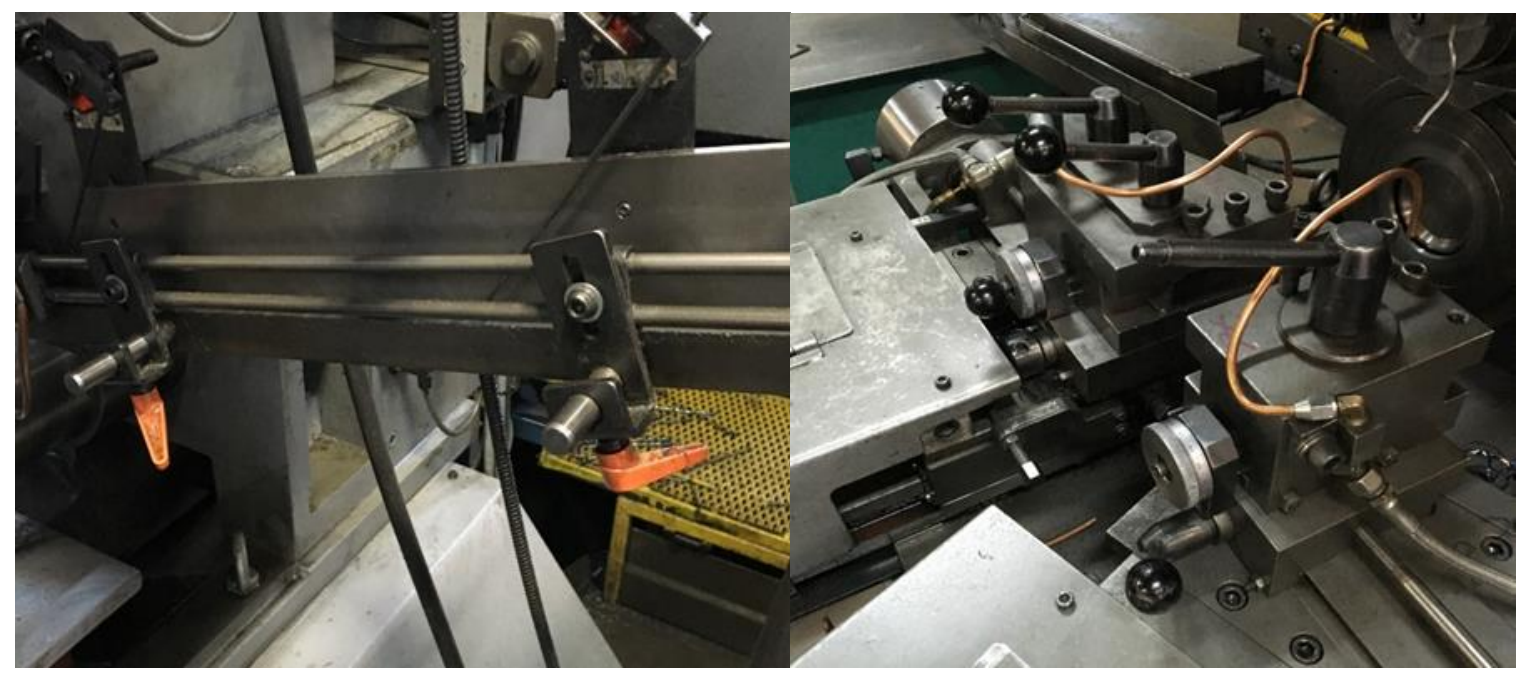

Figure 7. The development equipment for bolts

During the setup phase, it was discovered that too much time was wasted because of the long distance between the turning line and measurement room. In order to solve this problem, a meeting was held with the quality assurance management team. In the meeting, SMED team members agreed on transferring of measurement operation which had previously been performed in measurement room. Therefore, the dial/digital indicator devices were provided to turning machine operators. Six of the turning machine operators were trained by the quality department for a month. A place for these measurement devices was reserved in a close proximity to the line A. At the end of this application, time loss due to this measurement operation was reduced from 182 minutes to 42 minutes. Thus, 140 minutes of useful time was gained. The SMED application stages and the activities carried out at each stage are given in Figure 8. 

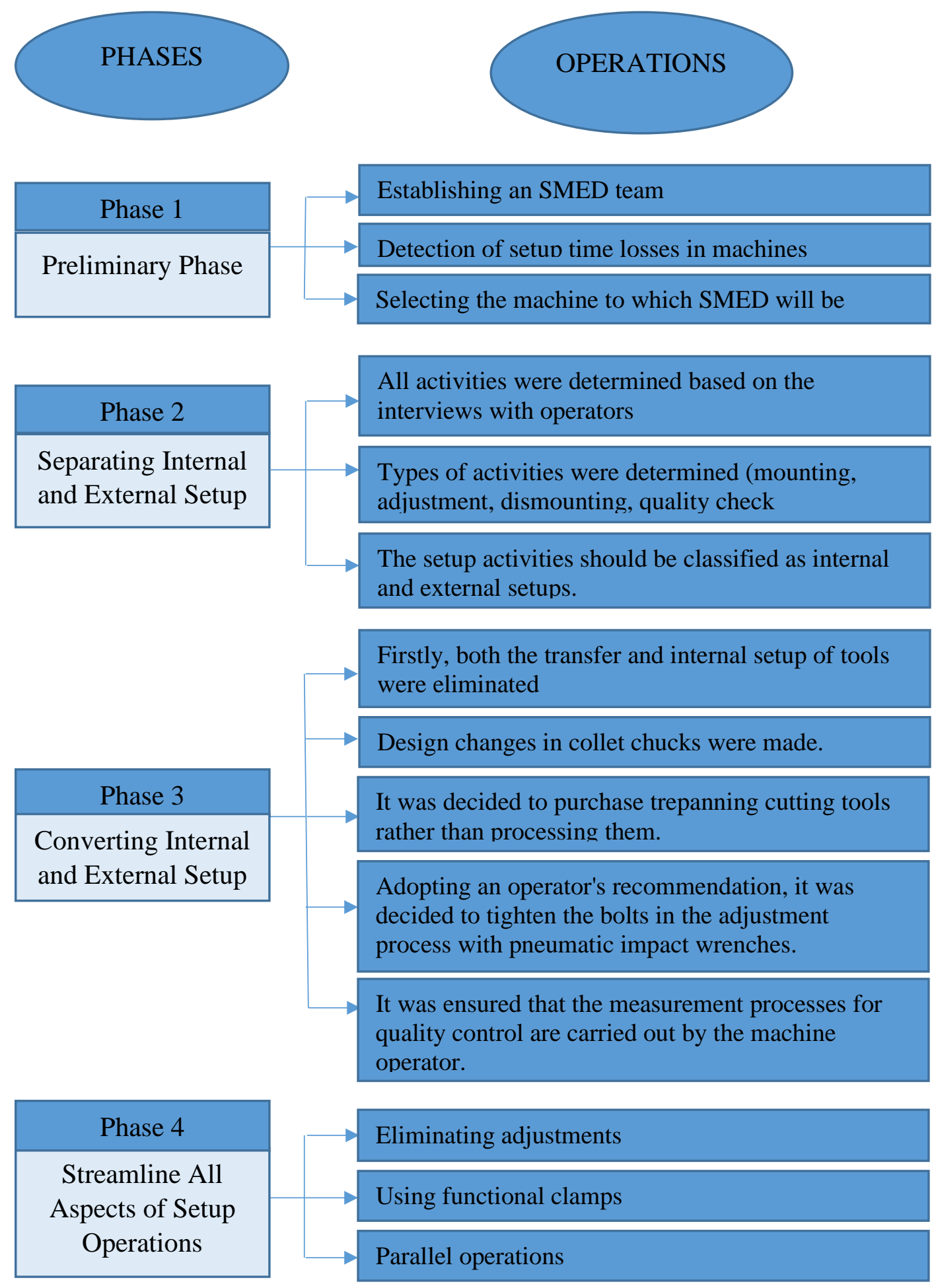

Figure 8. SMED conceptual stages and practical activities

At the end of all SMED applications in the company, total setup time was reduced from 1418 minutes to 930 minutes. Namely, approximately 34.42 percent improvement has been achieved, which equates to almost 8 man-hours of workload. The breakdown of the improvements achieved is summarized in Table 1. When these setups were distributed among two setup operators, the operators could complete these tasks within 749 minutes. Right after these improvements, setup completion time with two operators was reduced to 482 minutes. However, SMED team realized that if task assignment of setup operators were improved, further reduction of total setup time would be possible. Then, the task assignments of operators were 
changed. After this change, the total setup time with the two operators was reduced by another 3.32 percent to 466 minutes.

Table 1. Reduction of setup times

\begin{tabular}{lccc}
\hline Improvement & $\begin{array}{l}\text { Before } \\
\text { SMED } \\
\text { (minutes) }\end{array}$ & $\begin{array}{l}\text { After } \\
\text { SMED } \\
\text { (minutes) }\end{array}$ & $\begin{array}{l}\text { Improvement } \\
\text { (minutes) }\end{array}$ \\
\hline $\begin{array}{l}\text { Tools are provided just before they are needed } \\
\text { Elimination of cutting tool sharpening. Cutting tools }\end{array}$ & 10 & 0 & 10 \\
are purchased from a supplier. & 19 & 0 & 19 \\
$\begin{array}{l}\text { Collet chucks are machined before the setup. } \\
\text { Measurement devices were transferred to a closer }\end{array}$ & 918 & 627 & 291 \\
location to the trepanning line. & 182 & 42 & 140 \\
Simplification of bolt tightening/loosening & 289 & 261 & 28 \\
\hline TOTAL & 1418 & 930 & 488 \\
\hline
\end{tabular}

\section{CONCLUSION}

In this study, SMED methodology was performed to prepare an optimal standard procedure for changeover operations on a specified production line. Alternative ways to shorten internal setups was investigated in detail. In order to eliminate adjustment steps, trial and errors was minimized too. After SMED implementations, setup time was decreased from 1418 minutes to 930 minutes for a trepanning line of a ball bearing manufacturer. It was also observed that the changeover time was reduced from 749 to 466 minutes if two operators work concurrently and if works distribution among them is done properly. This study is a good example of successful SMED implementations in a ball bearing factory.

After seeing the results of the SMED implementation, managers should generalize such practices in other parts of the factory. They can make big gains by making very small adjustments and changes. By applying modern production philosophies such as lean manufacturing, they can increase the competitiveness of their businesses, use their scarce resources more effectively, and create additional resources to grow their factories.

As further studies, all the concepts of lean manufacturing such as SMED, 5S can be combined with the Industry 4.0 methodology. In this way, more effective and efficient processes can be designed for manufacturing and service companies.

\section{CONFLICTS OF INTEREST}

No conflict of interest was declared by the authors.

\section{ACKNOWLEDGMENT}

This paper has been produced from MSc. thesis titled "Yalın üretim ve imalat sektöründe bir uygulama" which carried out at Gazi University, Graduate School of Natural and Applied Sciences.

\section{REFERENCES}

[1] Dave, Y., Sohani, N., "Single Minute Exchange of Dies: Literature Review", International Journal of Lean Thinking, 3(2): 27-37, (2012).

[2] Chong, M. Y., Chin, J. F., Loh, W.P., "Lean Incipience Spiral Model for Small and Medium Enterprises", International Journal of Industrial Engineering: Theory, Applications and Practice, 20(7-8): 487-501, (2013). 
[3] Sherali, H. D., Van Goubergen, D., Van Landeghem, H., "A quantitative approach for scheduling activities to reduce set-up in multiple machine lines", European Journal of Operational Research, 187(3): 1224-1237, (2008).

[4] Ulutaş, B., "An application of SMED Methodology", World Academy of Science, Engineering and Technology, 5(7): 63-66, (2011).

[5] Pellegrini, S., Shetty, D., Manzione, L., "Study and Implementation of Single Minute Exchange of Die (SMED) Methodology in a Setup Reduction Kaizen", Proceedings of the $3^{\text {rd }}$ International Conference on Industrial Engineering and Operations Management, İstanbul, Türkiye, July 3-6, 2353-2363, (2012).

[6] Okur, A. S., Yalın üretim: 2000'li yıllara doğru Türkiye sanayii için yapılanma modeli, Söz Yayın Oyunajans, Türkiye, (1997).

[7] Van Goubergen, D., Van Landeghem, H., "Rules for integrating fast changeover capabilities into new equipment design", Robotics and Computer-Integrated Manufacturing, 18(3-4): 205-214, (2002).

[8] Trovinger, S. C., Bohn, R. E., "Setup Time Reduction for Electronics Assembly: Combining Simple (SMED) and IT-Based Methods", Production and Operations Management, 14(2): 205-217, (2005).

[9] McIntosh, R., Owen, G., Culley, S., Mileham, T., "Changeover improvement: Reinterpreting Shingo's "SMED" methodology", IEEE Transactions on Engineering Management, 54(1): 98-111, (2007).

[10] Cakmakci, M., "Process improvement: performance analysis of the setup time reduction-SMED in the automobile industry", The International Journal of Advanced Manufacturing Technology, 41(12): 168-179, (2009).

[11] Kusar, J., Berlec, T., Zefran, F., Starbek, M., "Reduction of Machine Setup Time", Strojniski Vestnik-Journal of Mechanical Engineering, 56(12): 833-845, (2010).

[12] Deros, B. M., Mohamad, D., Idris, M. H. M., Rahman, M. N. A., Ghani, J. A., Ismail, A. R., "Setup Time Reduction in an Automotive Battery Assembly Line", International Journal of Systems Applications, Engineering \& Development, 5(5): 618-625, (2011).

[13] Abraham, A., Ganapathi, K.N., Kailash, M., "Setup Time Reduction Through SMED Technique in a Stamping Production Line", SASTech-Technical Journal, 11(2): 47-52, (2012).

[14] Van Goubergen, D., Van Landeghem, H., “An integrated methodology for more effective set-up reduction”, In: IIE Solutions, IIE Annual Conference Proceedings, May 21-23, Dallas, TX, (2001).

[15] Bevilacqua, M., Ciarapica, F., De Sanctis, I., Mazzuto, G., Paciarotti, C., "A Changeover Time Reduction through an integration of lean practices: a case study from pharmaceutical sector", Assembly Automation, 35(1): 22-34, (2015).

[16] Filla, J., "The Single Minute Exchange of Die Methodology in a High-Mix Processing Line", Journal of Competitiveness, 8(2): 59-69, (2016).

[17] Soberi, M. S. F., Ahmad, R., "Integration of SMED with AHP: a case study in an aerospace company", Journal of Engineering Research and Education, 9: 41-52, (2017). 
[18] Karasu, M., Salum, L., "FIS-SMED: a fuzzy inference system application for plastic injection mold changeover", The International Journal of Advanced Manufacturing Technology, 94: 545-559, (2018).

[19] Otur, B., Yildirim, I. S., Ayhan, M. B., "Single minutes exchange of die (smed) applications at the color changeover process of plastic bottles", Press Academia Procedia (PAP), 7: 233-236, (2018).

[20] Monteiro, C., Ferreira, L. P., Fernandes, N. O., Sá, J. C., Ribeiro, M. T., Silva, F. J. G., "Improving the machining process of the metalworking industry using the lean tool smed", Procedia Manufacturing, 41: 555-562, (2019).

[21] Vieira, T., Sá, J.C., Lopes, M.P., Santos, G., Félix, M.J., Ferreira, L.P., Silva, F.J.G., Pereira, M.T., "Optimization of the cold profiling process through SMED", Procedia Manufacturing, 38: 892-899, (2019).

[22] Akyurt, İ.Z., Eren, E., "Hazırlık Süresinin Azaltılmasında SMED Yöntemi Uygulaması”, Ekonomik ve Sosyal Araştırmalar Dergisi, 15(3): 315-331, (2019).

[23] Çelik, H., “Ayar sürelerinin azaltılmasına yönelik yeni yaklaşım: SMED Taguchi yöntemi”, Sakarya Üniversitesi İşletme Enstitüsü Dergisi, 2(1): 13-26, (2020).

[24] Yalçın, S.E., Akın, S., Elmas, B., Eren, M., Gündüz, T., "Boru İmalatında Hazırlık Sürelerine Yönelik Yalın Üretim ve SMED Çalışması”, Endüstri Mühendisliği, 31(1): 87-104, (2020).

[25] Vieira, A.M., Silva, F.J.G., Campilho, R.D.S.G., Ferreira, L.P., Sá, J.C., Pereira, T., "SMED methodology applied to the deep drawing process in the automotive industry", Procedia Manufacturing, 51: 1416-1422, (2020).

[26] Godina, R., Pimentel, C., Silva, F. J. G., Matias, J. C. O., "A structural literature review of the single minute exchange of die: the latest trends", Procedia Manufacturing, 17: 783-790, (2018).

[27] da Silva, I. B., Godinho Filho, M., "Single-minute exchange of die (SMED): a state-of-the-art literature review", The International Journal of Advanced Manufacturing Technology, 102: 42894307, (2019).

[28] Shingo, S., “A Revolution in Manufacturing: The SMED System”, Productivity Press, New York, NY, USA, (1985). 